DOI:

\title{
Perancangan Sistem Informasi Akuntansi Kredit Konsumtif Dengan Menggunakan Software Microsoft Visual Basic 6.0 dan SQL Server 2000 Berbasis Client Service
}

\author{
Ridwan Setiawan ${ }^{1}$, Hery Dwi Yulianto ${ }^{2}$ \\ Program Studi Komputerisasi Akuntansi \\ Fakultas Teknik dan Ilmu Komputer - Universitas Komputer Indonesia \\ E-mail: hery.dwi.yulianto@email.unikom.ac.id
}

\section{Keywords: \\ Design of Costumer, Loan Accounting Information System, Microsoft Visual Basic 6.0, SQL server, accounting}

\begin{abstract}
PT BPR Metro Asia Mandiri wich is located at Jl. Raya Soekarno-Hatta Bandung, Phone.022-7537668 Fax. 022-7537670. Int the time of executing the recording and calculating the costumer loan transacton, PT BPR Metro Asia Mandiri uses Microsoft Excel.These problems will result uneffective and unoptimal.To reduce these problems, the writer takes the title "Perancangan Sistem Informasi Akuntansi Kredit Konsumtif dengan Menggunakan Software Microsoft Visual Basic 6.0 dan SQL Server 2000 Berbasis Client Server".

As the research design the author uses research design with primary/secondary daya, the author uses qualitative data ande quantitative data, the author uses exploratory ande descriptive research as a research method, for data collection techniques the writer uses field studies consinting of interviews, obsrvation dand literature studies, the author using process, data and output oriented methodologies. The author use the waterfall model as a system design structure. Information system degin use contxt diagrams, data flow diagrams, data dictionaries, flow diagram, normalization and Entity Relationshop Diagrams.
\end{abstract}

\footnotetext{
Abstrak

PT BPR Metro Asia Mandiri berada di Jl. Raya Soekarno-Hatta Bandung. Telp. 022-7537668 Fax. 022-7537670. PT BPR Metro Asia Mandiri menggunakan microsoft excel. Hal tersebut bermasalah menjadi tidak efektif dan tidak optimal. Untuk mngurangi masalah tersebut, penulis mengambil judul "Perancangan Sistem Informasi Akuntansi Kredit Konsumtif dengan Menggunakan Software Microsoft Visual Basic 6.0 dan SQL Server 2000 Berbasis Client Server"

Sebagai penulis penelitian menggunakan desain pengenelitian dengan penelitian primer/sekunder, penulis menggunakan data kualitatif dan kuantitatif, penulis menggunakan penelitian eksplorasi dan metode penelitian, untuk teknik pengumpulan data penulis menggunakan studi lapangan yang terdiri dari wawancara, obsesi dan studi literatur, penulis menggunakan metodology berorientasi proses, data dan output. Penulis menggunakan model waterfall sebagai struktur desain sistem. Sistem informasi menggunakan diagram konteks, diagram aliran data, kamus data, diagram alir, normaliasi, dan Entity Relationship Diagram.
} 
Nama penulis : Hery Dwi yulianto, Ridwan Setiawan

Judul : Perancangan Sistem Informasi Akuntansi Kredit Konsumtif Dengan Menggunakan

Software Microsoft Visual Basic 6.0 dan

SQL Server 2000 Berbasis Client Server
Jurnal @ is The Best

Vol. 04 No. 01. Juni 2019: Hal 396-410

E-ISSN : 2252-9853

\section{Pendahuluan}

Seiring perkembangan teknologi yang sangat pesat, manusia membutuhkan sebuah teknologi dan sistem informasi yang dapat mempermudah dan mempercepat dalam bekerja sehingga menghasilkan informasi lebih akurat. Perusahaan membutuhkan sebuah sistem informasi akuntansi untuk mengolah data atau transaksi yang terjadi guna menghasilkan sebuah laporan keuangan yang bermanfaat dan berkualitas.

PT BPR Asia Mandiri beralamatkan di Jl. Soekarno hatta No.590 Bandung merupakan sebuah perusahaan yang bergerak dibidang perbankan terutama dalam usaha perkreditan. Kredit konsumtif adalah piutang serta asset yang dimiliki oleh perusahaan perkreditan. Kegiatan dalam sistem perkreditan yang telah dilakukan pada perusahaan tersebut sebelumnya telah dilakukan melalui komputerisasi, namun belum terintegrasi antara bagian kredit dengan bagian akuntansi sehingga memakan waktu yang cukup lama untuk mengerjakan laporan keuangan. Selain itu, belum ada kegiatan pembuatan laporan pendapatan kredit konsumtif dan kartu piutang kredit konsumtif.

Berdasarkan uraian di atas, penulis melakukan penelitian dengan judul "Perancangan Sistem Informasi Akuntansi Kredit Konsumtif Pada PT BPR Metro Asia Mandiri Dengan Menggunakan Software Microsoft Visual Basic 6.0 Dan SQL Server 2000 Berbasis Client Server".

\section{Identifikasi Masalah}

A. Bagaimana penerapan Sistem Informasi Akuntansi Kredit Konsumtif Pada PT BPR Metro Asia Mandiri.

B. Bagaimana Perancangan Sistem Informasi Akuntansi Kredit Konsumtif Pada PT BPR Metro Asia Mandiri dengan Menggunakan Microsoft Visual Basic 6.0 dan SQL Server 2000 berbasis Client Server.

\section{Batasan Masalah}

A. Membahas penerapan sistem informasi akuntansi kredit konsumtif pada PT BPR Metro Asia Mandiri.

B. Membahas Perancangan Sistem Informasi Akuntansi Kredit Konsumtif Pada PT BPR Metro Asia Mandiri Dengan Menggunakan Microsoft Visual Basic 6.0 dan SQL Server 2000 berbasis Client Server.

\section{Tujuan Penelitian}

A. Untuk mengetahui penerapan sistem informasi akuntansi kredit konsumtif pada PT BPR Metro Asia Mandiri.

B. Untuk merancang Sistem Informasi Akuntansi Kredit Konsumtif Pada PT BPR Metro Asia Mandiri Dengan Menggunakan Microsoft Visual Basic 6.0 dan SQL Server 2000 berbasis Client Server.

\section{Kerangka Teoritis Dan Pengembangan Hipotesis}

\section{Perancangan}

Menurut Al-Bahra bin Ladjmudin, "perancangan (design) memiliki tujuan untuk mendesain sistem baru yang dapat menyelesaikan masalah-masalah yang dihadapi perusahaan yang diperoleh dari pemilih alternatif sistem yang terbaik"'[1]. 
Berdasarkan uraian di atas, maka penulis dapat menyimpulkan bahwa perancangan merupakan suatu kegiatan meremcanakan maupun mengembangkan suatu sistem yang dapat menyelesaikan masalah-masalah yang terjadi.

\section{Sistem}

Menurut Al-Bahra bin Ladjmudin, "sistem adalah kumpulan dari komponen atau elemenelemen atau subsistem-subsistem"[1]. Sedangkan menurut Jogiyanto H.M., "sistem adalah kumpulan elemen-elemen yang berinteraksi untuk mencapai suatu tujuan tertentu"[2].

\section{Informasi}

Menurut Jogiyanto H.M., "informasi adalah data yang diolah menjadi bentk yang lebih berguna dan lebih berarti bagi yang menerimanya"[2]. Sedangkan menurut Krismiaji, "informasi adalah data yang telah diorganisasikan dan telah memiliki kegunaan dan manfaat"[3].

Berdasarkan uraian di atas, maka penulis menyimpulkan bahwa informasi merupakan data yang telah diolah menjadi sesuatu yang dapat memberikan manfaat dan dipahami bagi yang menerimanya.

\section{Sistem Informasi}

Menurut Jogiyanto H.M., "sistem informasi adalah suatu sistem di dalam suatu organisasi yang mempertemukan kebutuhan pengolahan transaksi harian, mendukung operasi, bersifat manajerial dan kegiatan strategi dari suatu organisasi dan menyediakan pihak luar tertentu dengan laporan-laporan yang diperlukan"[2].

Berdasarkan uraian di atas, maka penulis menyimpulkan bahwa sistem informasi merupakan suatu sistem yang berasal dari kumpulan data yang telah diolah menjadi informasi yang bermanfaat bagi penerimanya.

\section{Akuntansi}

Menurut Soemarso, "akuntansi adalah proses mengidentifikasikan, mengukur dan melaporkan informasi ekonomi, untuk memungkinkan adanya penilaian dan keputusan yang jelas dan tegas bagi mereka yang menggunakan informasi tersebut'[4].

Berdasarkan uraian di atas, maka penulis menyimpulkan bahwa akuntansi merupakan kegiatan mencatat, identifikasi, mengukur dan melaporkan aktivitas bisnis yang menyediakan informasi penting bagi perusahaan.

\section{Sistem Informasi Akuntansi}

Menurut Krismiaji, "sistem informasi akuntansi adalah sebuah sistem yang memproses data dan transaksi guna menghasilkan informasi yang bermanfaat untuk merencanakan, mengendalikan dan mengoperasikan bisnis"[3]. 

SQL Server 2000 Berbasis Client Server

Berdasarkan uraian di atas, maka penulis menyimpulkan bahwa sistem informasi akuntansi merupakan suatu sistem yang mengolah data akuntansi sehingga menghasilkan informasi keuangan yang bermanfaat bagi penerimanya.

\section{Kredit Konsumtif}

Menurut Bastian.I., "kredit konsumtif (costumer loan), adalah kredit yang diberikan untuk memenuhi kebutuhan debitor yang bersifat konsumtif'[5].

Berdasarkan uraian di atas, maka penulis menyimpulkan bahwa kredit konsumtif merupakan penyediaan uang tagiahan yang diberikan untuk memenuhi kebutuhan seseorang dan bersifat konsumtif.

\section{Sistem Informasi Akuntansi Kredit Konsumtif}

Sistem informasi kredit konsumtif adalah suatu sistem yang di dalamnya terdapat kumpulan komponen atau sub-sistem yang saling berkaitan dan menghasilkan sebuah informasi akuntansi kredit konsumtif yang dapat digunakan untuk mengambil keputusan suatu perusahaan.

\section{Perancangan Sistem Informasi Kredit Konsumtif}

Perancangan sistem informasi akuntansi kredit adalah merencanakan atau mengembangkan suatu sistem informasi yang telah ada menjadi suatu sistem yang dapat memproses data transaksi dan kegiatan kredit konsumtif sehingga akan menghasilkan informasi mengenai laporan keuangan akuntansi kredit konsumtif.

\section{Metode}

\section{Unit Analisis}

Penulis melakukan pencarian dan mengumpulkan data yang berkaitan dengan kredit konsumtif pada PT BPR Metro Asia Mandiri serta dibuatkan perancangan program berupa sistem informasi yang dapat bermanfaat.

\section{Populasi dan Sampel}

Populasi dalam penelitian ini yaitu laporan keuangan neraca tahun 2007-2010. Sedangkan sampel yang digunakan adalah laporan keuangan neraca tahun 2009 karena ada keterbatasan perusahaan dalam mempublikaskan laporan keuangan.

\section{Objek Penelitian}

Objek penelitian difokuskan pada Sistem Informasi Akuntansi Kredit Konsumtif pada PT BPR Metro Asia Mandiri Dengan Menggunakan Software Microsoft Visual Basic 6.0 dan SQL Server 2000. 


\section{Desain Penelitian}

Menurut Nazir, M, menjelaskan bahwa:

"Dalam desain sampling ini termasuk: a) mendefinisikan populasi, b) menentukan besarnya sampel, dan c) menentukan sample yang representative. Desain dari instrument atau alat, yang dimaksud alat disini adalah alat untuk mengumpulkan data. Desain analisis, secara ideal desain analisis sudah dikerjakan lebih dahulu sebelum pengumpulan data dimulai” [6].

Desain penelitian yang penulis gunakan adalah desain penelitian sampel.

\section{Metode Penelitian}

Metode penelitian eksplanatoris merupakan penelitian yang dilakukan dengan menyempurnakan atau mengembangkan metode kerja dari peneliti sebelumnya agar lebih efektif dan efisien. Metode penelitian deskriftif menceritakan hasil penelitian dalam bentuk tulisan atau karya ilmiah. Metode survei merupakan penelitian langsung ke lapangan untuk memperoleh data.

\section{Teknik Pengumpulan Data}

A. Penelitian Lapangan (Field Research)

1) Wawancara (interview)

2) Pengamatan (observation)

B. Penelitian Kepustakaan (Library Research)

\section{Metodologi Pengembangan Sistem}

Menurut Mulyadi, "metodologi pengembangan sistem adalah langkah-langkah yang dilalui oleh analisis sistem dalam mengembangkan sistem informasi" [7].

\section{Model Pengembangan Sistem}

Model pengembangan sistem yang digunakan oleh penulis adalah Model Sekuensial Linier (Waterfall Mode), karena tahapan-tahapan untuk membangun sebuah sistem tersebut mudah dipahami. 

Kredit Konsumtif Dengan Menggunakan Software Microsoft Visual Basic 6.0 dan SQL Server 2000 Berbasis Client Server

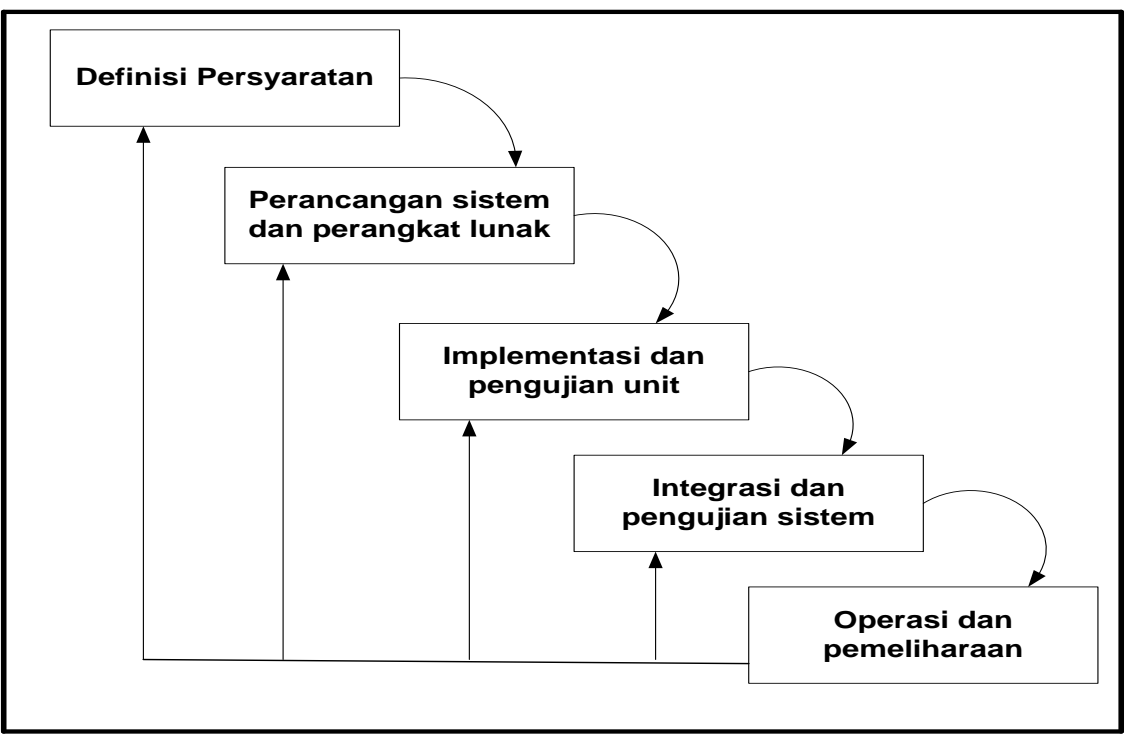

Gambar 1 Model Sekuensial Linier (W aterfall Moded)

\section{Lokasi dan Waktu}

Penelitian berlangsung di PT BPR Metro Asia Mandiri yang beralamat di Jl. Soekarno Hatta No. 590 MTC D.16 Bandung 40286. Dengan waktu penelitian yang dimulai dari bulan Desember 2010 hingga bulan Februari 2012.

\section{Hasil Dan Pembahasan}

\section{Analisis Sistem yang Berjalan}

\section{A. Struktur Organisasi Berjalan}

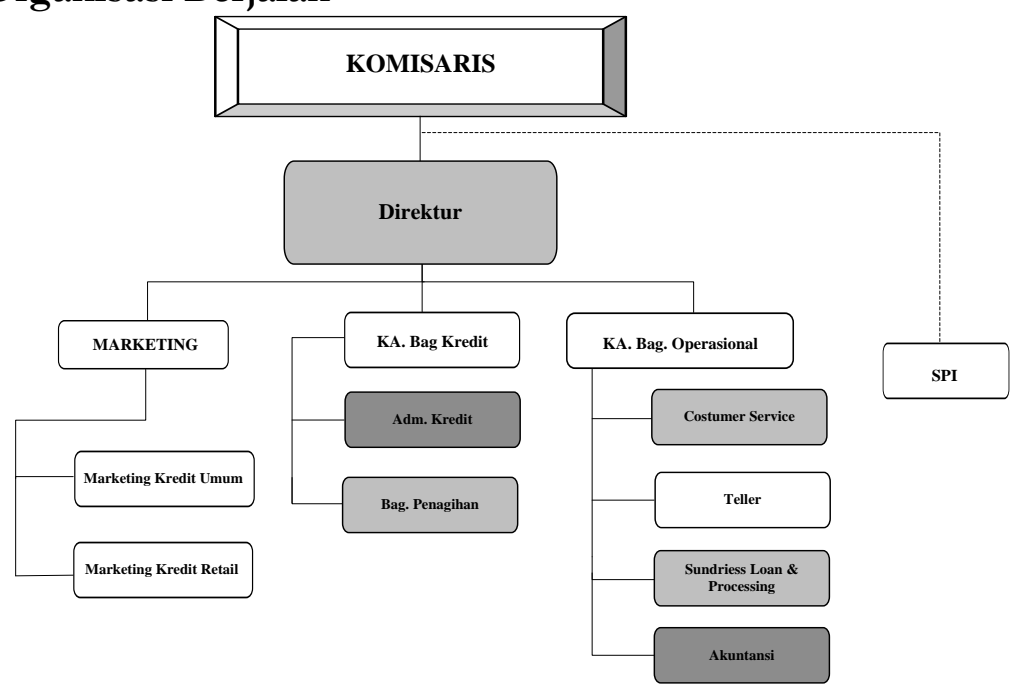

Gambar 2 Struktur Organisasi Berjalan

\section{Perancangan Sistem Informasi Akuntansi Kredit Konsumtif}

A. Formulir/Dokumen dan Catatan yang diusulkan 
Nama penulis : Hery Dwi yulianto, Ridwan Setiawan

Judul : Perancangan Sistem Informasi Akuntansi Kredit Konsumtif Dengan Menggunakan Software Microsoft Visual Basic 6.0 dan SQL Server 2000 Berbasis Client Server
Jurnal @ is The Best Vol. 04 No. 01. Juni 2019: Hal 396-410

E-ISSN : 2252-9853

1) Dokumen Permohonan Kredit.

2) Memorandum Analisa Kredit.

3) Memorandum Persetujuan Kredit.

4) Bukti Realisasi Kredit.

5) Bukti Angsuran Kredit.

6) Dokumen Rekapitulasi Kredit.

7) Laporan Pendapatan Kredit Konsumtif.

8) Jurnal Umum.

9) Buku Besar Umum.

10) Laporan Neraca.

11) Laporan Kredit Konsumtif.

B. Diagram Alur Data yang Diusulkan

1) Diagram Konteks yang Diusulkan

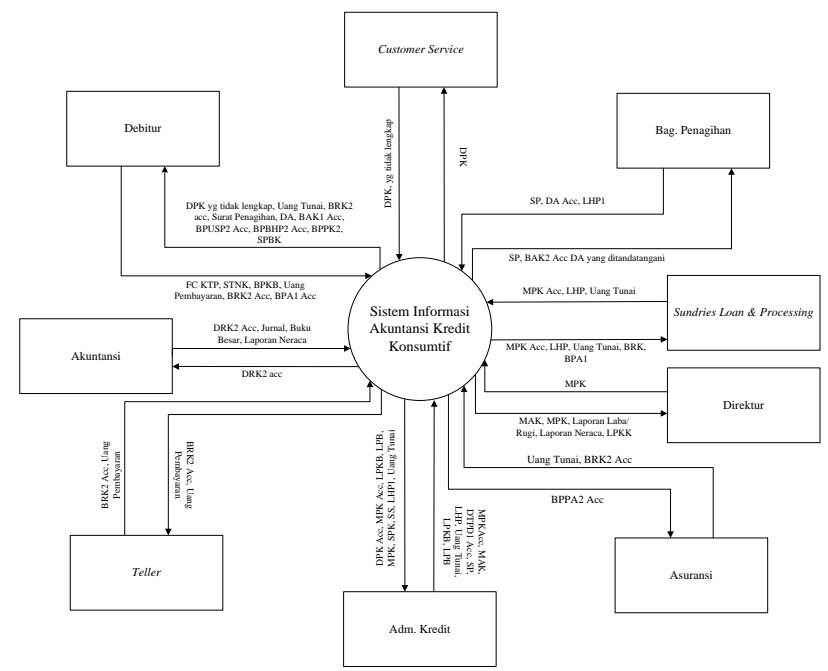

Gambar 3 Diagram Konteks yang Diusulkan 
Nama penulis : Hery Dwi yulianto, Ridwan Setiawan

Judul
: Perancangan Sistem Informasi Akuntansi Kredit Konsumtif Dengan Menggunakan Software Microsoft Visual Basic 6.0 dan SQL Server 2000 Berbasis Client Server
Jurnal @ is The Best Vol. 04 No. 01. Juni 2019: Hal 396-410

E-ISSN : 2252-9853

2) Data Flow Diagram Level 0 yang Diusulkan

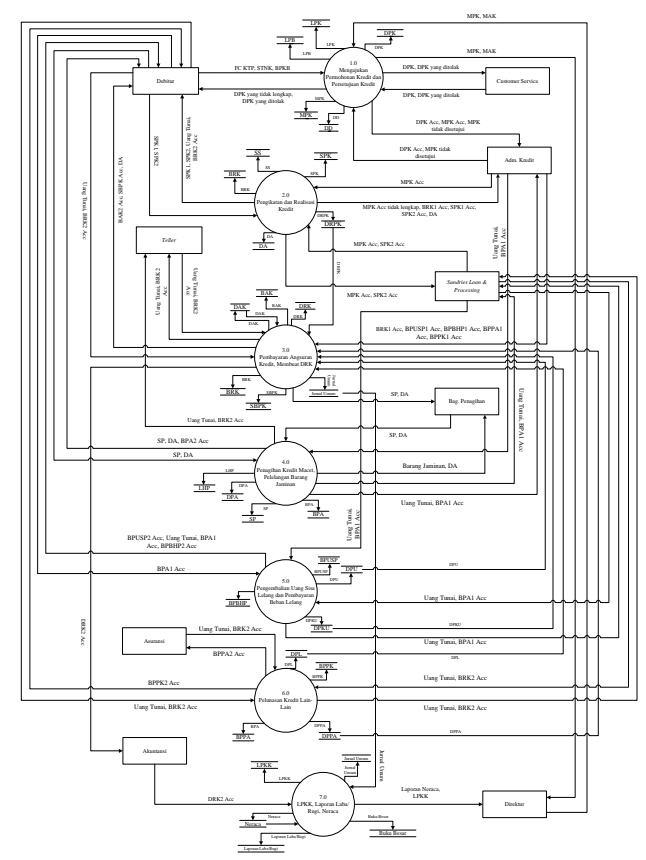

Gambar 4 Data Flow Diagram Level 0

Sistem Informasi Akuntansi Kredit Konsumtif yang Diusulkan

3) Bagan Alir (Flowchart) Sistem yang Diusulkan

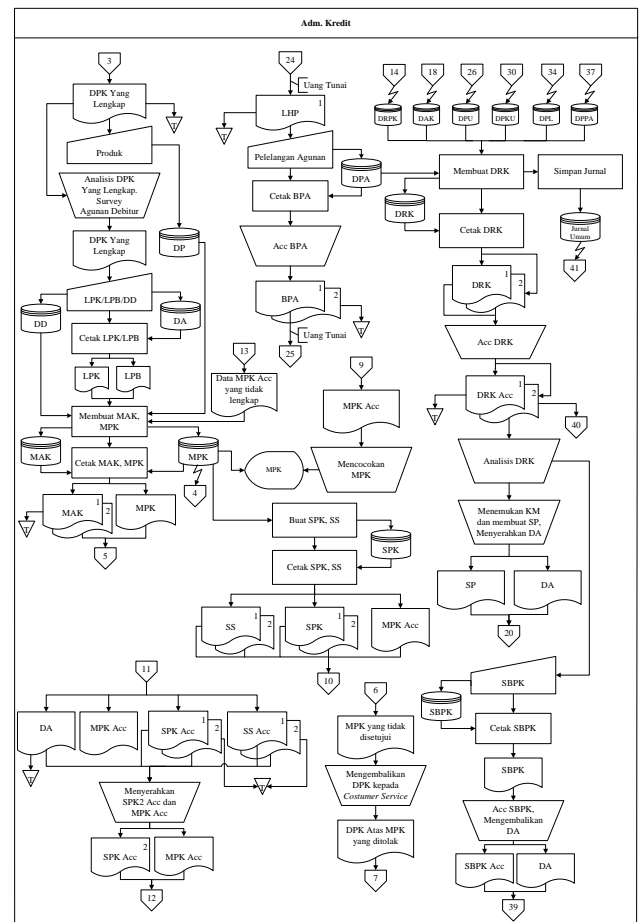

Gambar 5 Bagan Alir (Flowchart)

Sistem Informasi Akuntansi Kredit Konsumtif yang Diusulkan 2 
Nama penulis : Hery Dwi yulianto, Ridwan Setiawan

Judul

: Perancangan Sistem Informasi Akuntansi

Kredit Konsumtif Dengan Menggunakan

Software Microsoft Visual Basic 6.0 dan

SQL Server 2000 Berbasis Client Server
Jurnal @ is The Best

Vol. 04 No. 01. Juni 2019: Hal 396-410

E-ISSN : 2252-9853

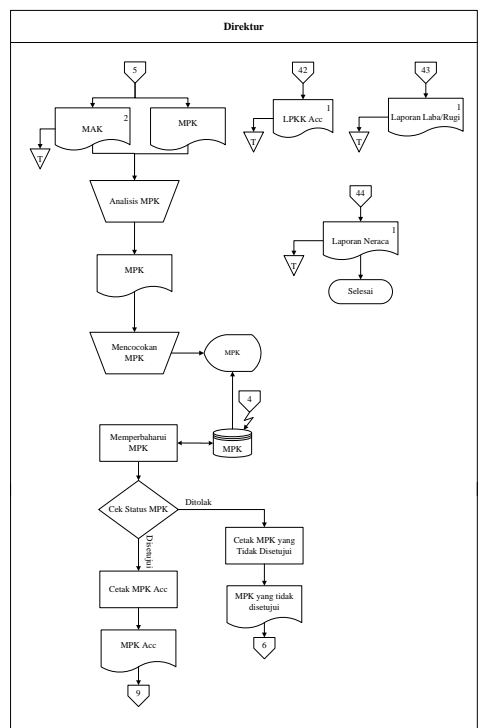

Gambar 6 Bagan Alir (Flowchart)

Sistem Informasi Akuntansi Kredit Konsumtif yang Diusulkan 8

4) Normalisasi yang Diusulkan

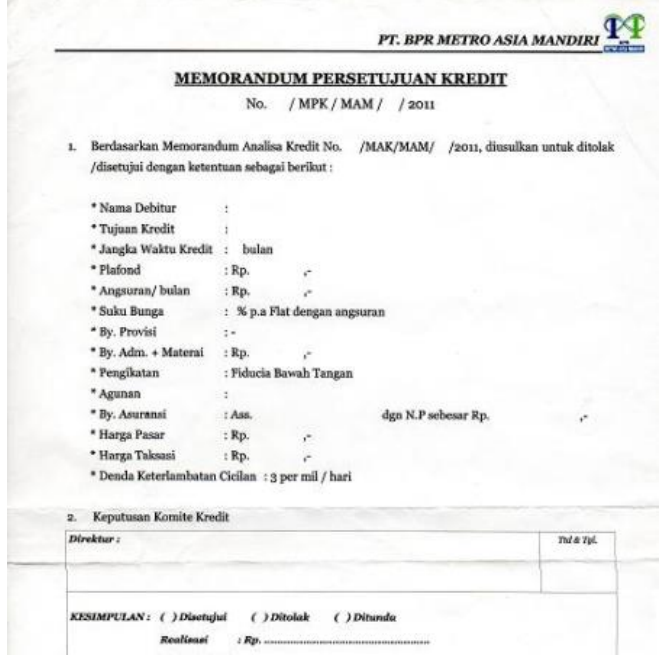

Gambar 7 MPK Unnormal

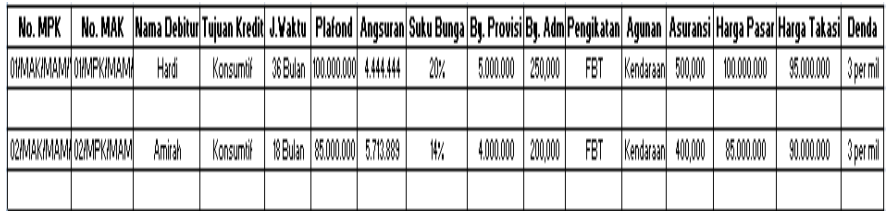

Tabel 1 Bentuk Unnormal 
Nama penulis : Hery Dwi yulianto, Ridwan Setiawan

Judul

: Perancangan Sistem Informasi Akuntansi Kredit Konsumtif Dengan Menggunakan

Software Microsoft Visual Basic 6.0 dan

SQL Server 2000 Berbasis Client Server
Jurnal @ is The Best

Vol. 04 No. 01. Juni 2019: Hal 396-410

E-ISSN : 2252-9853

\begin{tabular}{|c|c|c|c|}
\hline Nama Debitur & Agunan & Harga Pasar & Harga Takasi \\
\hline Hardi & Kendaraan & 100.000 .000 & 95.000 .000 \\
\hline & & & \\
\hline Amirah & Kendaraan & 85.000 .000 & 90.000 .000 \\
\hline & & & \\
\hline
\end{tabular}

Tabel 2 Realisasi 1 Tabel Debitur

5) Entity Relationship Diagram

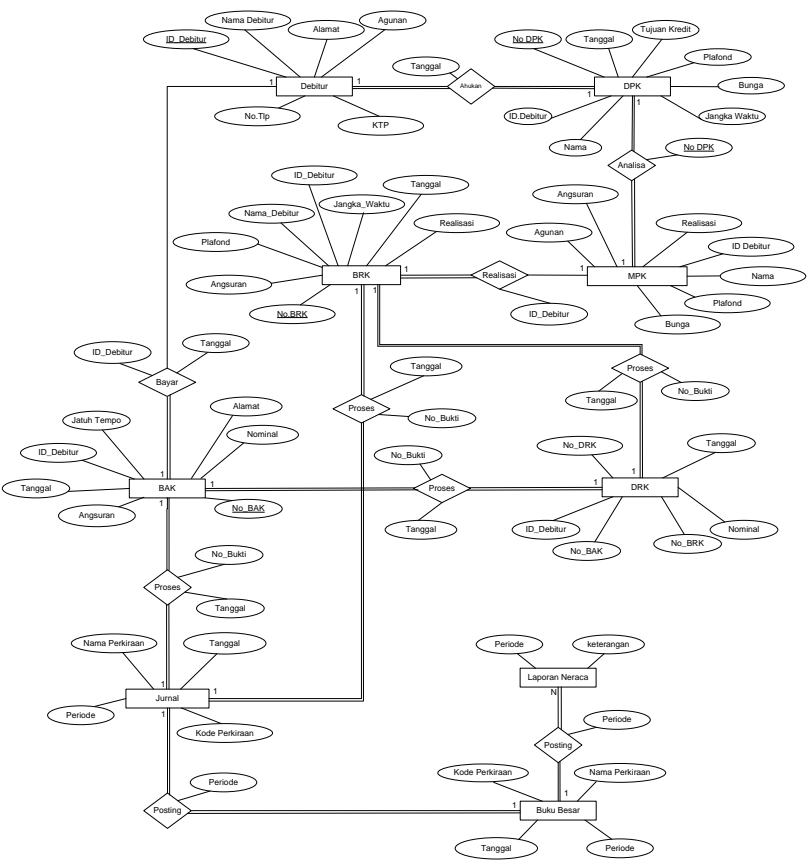

Gambar 8 Entity Relationship Diagram 
Nama penulis : Hery Dwi yulianto, Ridwan Setiawan

Judul

: Perancangan Sistem Informasi Akuntansi Kredit Konsumtif Dengan Menggunakan

Software Microsoft Visual Basic 6.0 dan SQL Server 2000 Berbasis Client Server
Jurnal @ is The Best Vol. 04 No. 01. Juni 2019: Hal 396-410

E-ISSN : 2252-9853

6) Struktur Menu Program

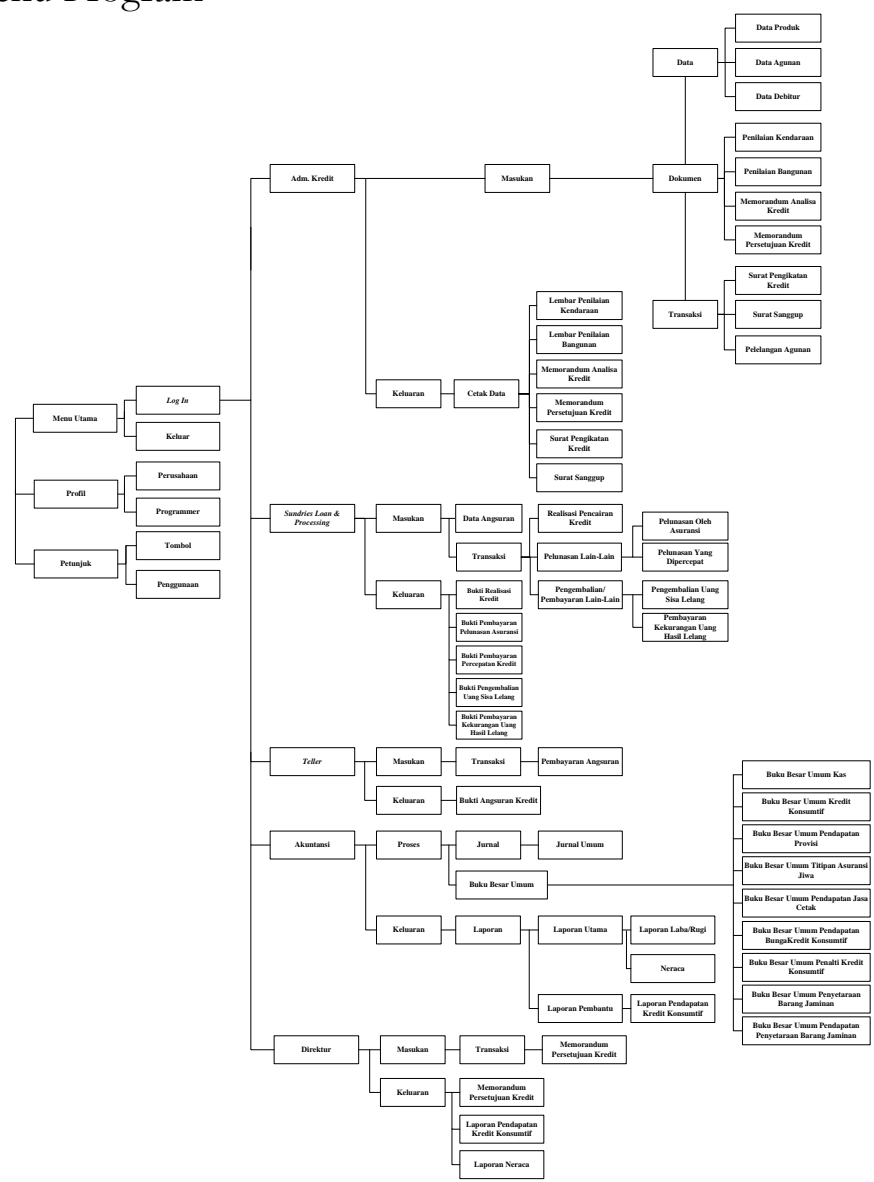

Gambar 9 Struktur Menu Program

7) Tampilan Menu Utama

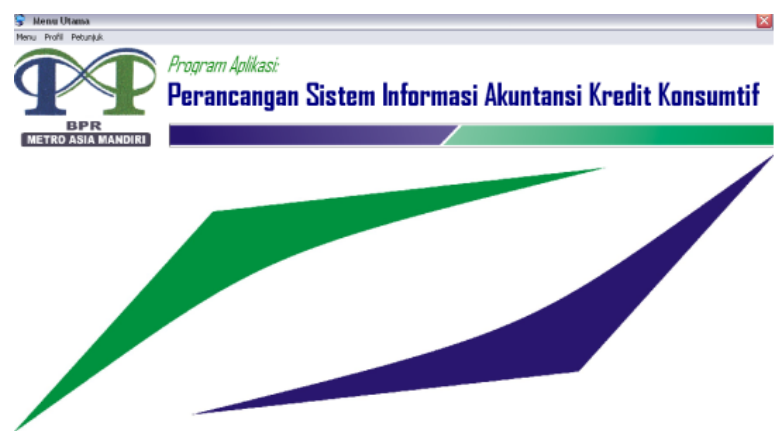

Gambar 10 Tampilan Pada Form Menu Utama 
Nama penulis : Hery Dwi yulianto, Ridwan Setiawan Judul
: Perancangan Sistem Informasi Akuntansi Kredit Konsumtif Dengan Menggunakan Software Microsoft Visual Basic 6.0 dan SQL Server 2000 Berbasis Client Server
Jurnal @ is The Best Vol. 04 No. 01. Juni 2019: Hal 396-410

E-ISSN : 2252-9853

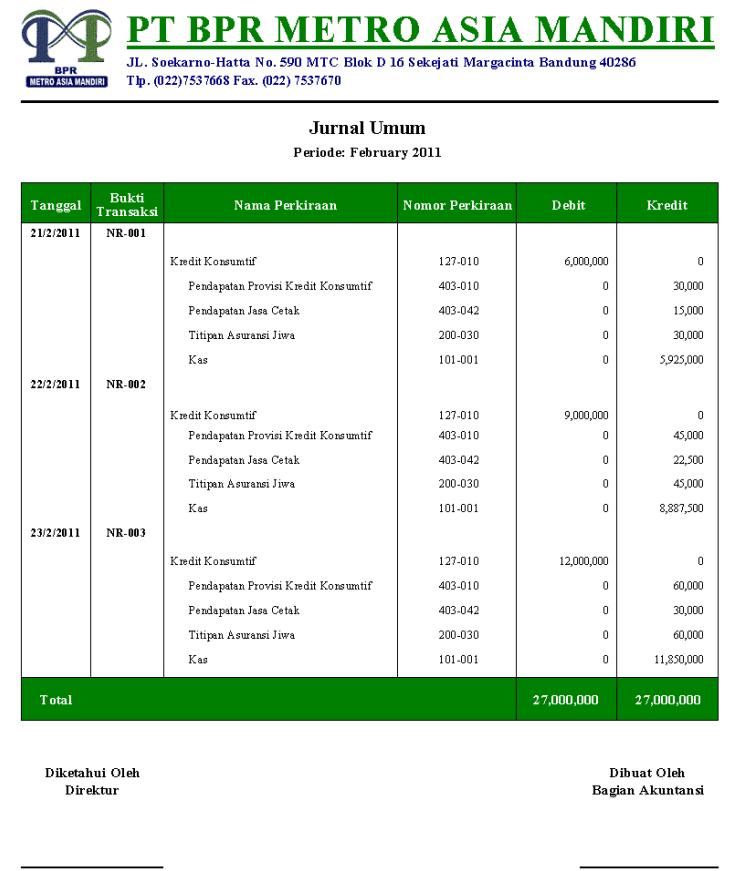

Gambar 11 Tampilan Pada Cetak Jurnal Umum Perbulan

P PT BPR METRO ASIA MANDIRI

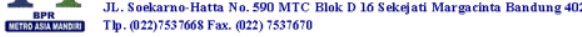

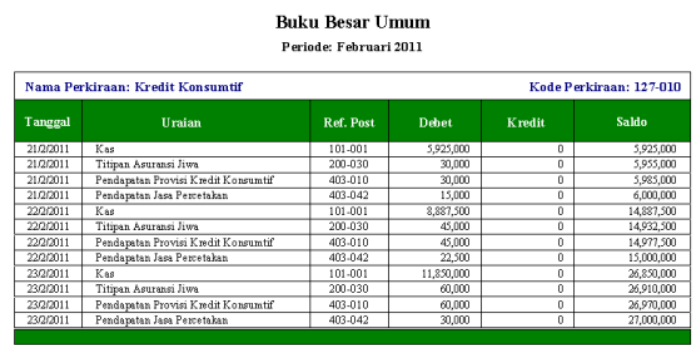

Diketahui Oleh

Dibuat Oleh
Bagian Akuntans

Gambar 12 Tampilan Pada Cetak Buku Besar Umum Kredit Konsumtif Perbulan

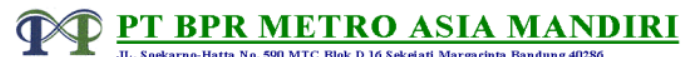

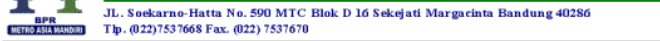

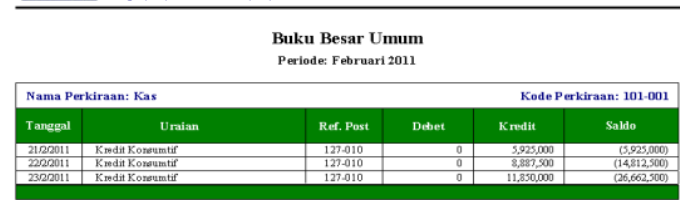

Diketahui oleh

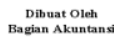

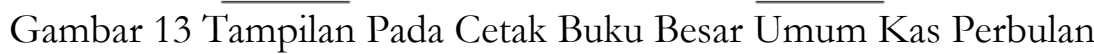


Nama penulis : Hery Dwi yulianto, Ridwan Setiawan

Judul
: Perancangan Sistem Informasi Akuntansi Kredit Konsumtif Dengan Menggunakan Software Microsoft Visual Basic 6.0 dan SQL Server 2000 Berbasis Client Server
Jurnal @ is The Best Vol. 04 No. 01. Juni 2019: Hal 396-410

E-ISSN : 2252-9853

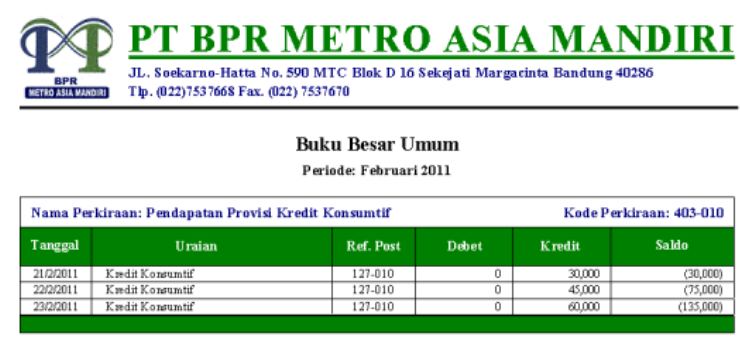

Diketahui Oleh Dibuat Oleh

Bagian Akuntansi

Gambar 14 Tampilan Pada Cetak Buku Besar Umum Pendapatan Provisi Kredit Konsumtif Perbulan
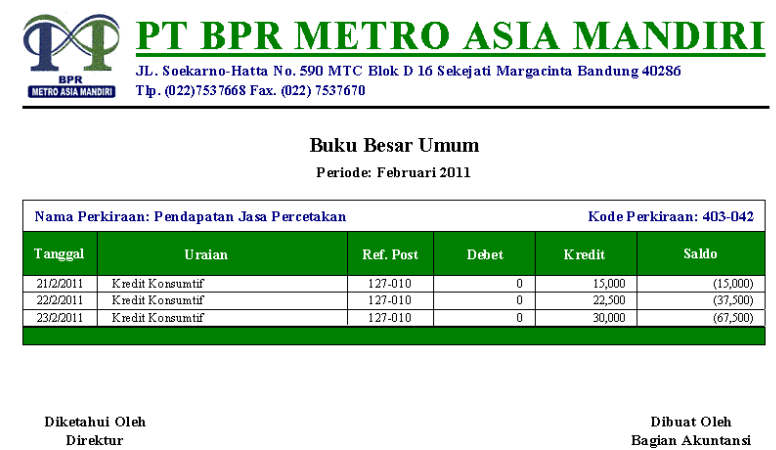

Gambar 15 Tampilan Pada Cetak Buku Besar Umum Pendapatan Jasa Percetakan Perbulan

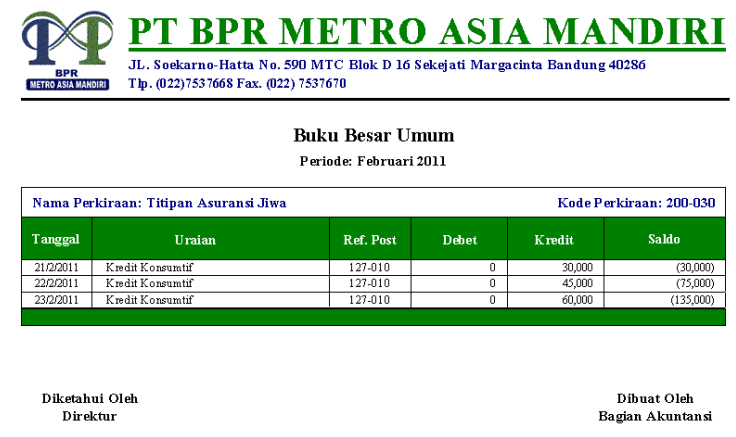

Gambar 16 Tampilan Pada Cetak Buku Besar Umum Titipan Asuransi Jiwa Perbulan 
Nama penulis : Hery Dwi yulianto, Ridwan Setiawan

Judul
: Perancangan Sistem Informasi Akuntansi Kredit Konsumtif Dengan Menggunakan Software Microsoft Visual Basic 6.0 dan SQL Server 2000 Berbasis Client Server
Jurnal @ is The Best Vol. 04 No. 01. Juni 2019: Hal 396-410

E-ISSN : 2252-9853

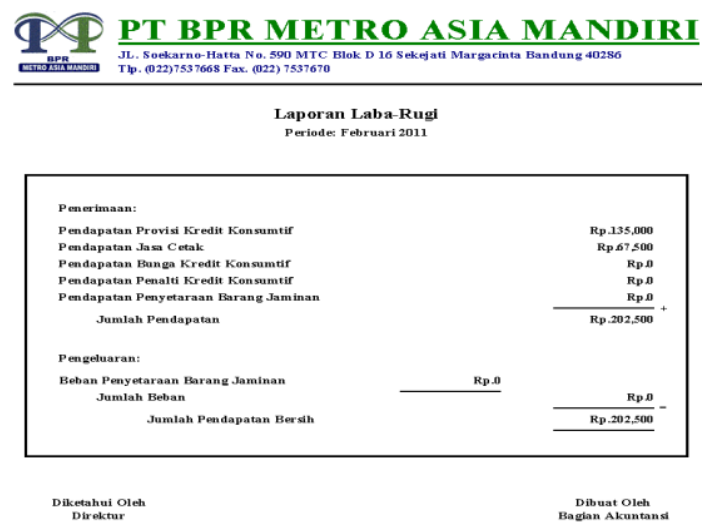

Gambar 17 Tampilan Pada Cetak Laporan Keuangan Laba Rugi Perbulan

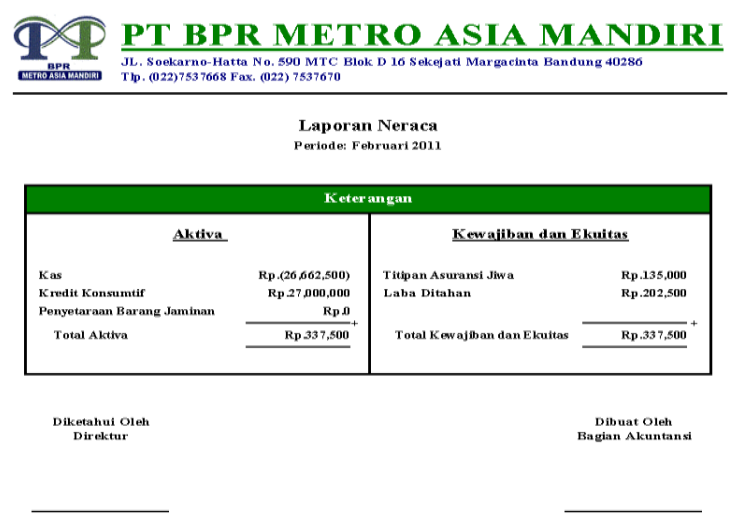

Gambar 18 Tampilan Pada Cetak Laporan Keuangan Neraca Perbulan 
Nama penulis : Hery Dwi yulianto, Ridwan Setiawan

Judul : Perancangan Sistem Informasi Akuntansi Kredit Konsumtif Dengan Menggunakan

Software Microsoft Visual Basic 6.0 dan SQL Server 2000 Berbasis Client Server
Jurnal @ is The Best Vol. 04 No. 01. Juni 2019: Hal 396-410

E-ISSN : 2252-9853

\section{Penutup}

Peneliti mencoba untuk meminimalkan permasalahan yang terjadi pada PT BPR Metro Asia Mandiri dengan membuatkan sebuah perancangan sistem informasi akuntansi kredit konsumtif dengan menggunakan Microsoft Visuat Basic 6.0 dan SQL Server 2000 sehingga dapat memaksimalkan pekerjaan dalam proses pembuatan laporan keuangan perusahaan tersebut.

Diperlukan adanya pengembangan terhadap aplikasi serta sumber daya manusia yang dapat mengelola aplikasi tersebut agar tetap berfungsi dengan baik.

\section{Daftar Pustaka}

[1] L. Bin and Al-Bahra, Analisis dan Desain Sistem Informasi. Yogyakarta: Graha Ilmu, 2005.

[2] H. . Jogiyanto, Analisis dan Desain Sistem Informasi. Yogyakarta: Andi Offset, 2005.

[3] Krismiaji, Sistem Informasi Akuntansi. Yogyakarta: Sekolah Tinggi Ilmu Ekonomi YKPN, 2005.

[4] Soemarso, Akuntansi Suatu Pengantar, Edisi 5. Jakarta: PT. Rimeka Cipta, 2004.

[5] Bastian, Akuntansi Sektor Publik. Jakarta: Erlangga, 2010.

[6] M. Nazir, Metode Penelitian. Jakarta: Ghalia Indonesia, 2005.

[7] Mulyadi, Sistem Akuntansi. Jakarta: Salemba Empat, 2001. 